\title{
Discussion on the Thoughts of Family and Country in Du Mu's Poems and Its Teaching Implications
}

\author{
Rong Xiaocuo \\ School of Literature, Xi'an University, Xi'an, Shaanxi, 710065
}

Keywords: Du Mu; Chang'an; Thought of the Country; Teaching Inspiration

\begin{abstract}
Chang'an which is the capital of Tang Dynasty is not only the hometown of Du Mu, but also the spiritual home that he needs most to realize his political ambitions. Therefore, it has become a concern for Du Mu's life. Du Mu's many poems written about Chang'an have both a deep thoughts on the hometown of Chang'an and a comprehensive display of the sights of the emperor, which contains the true feelings of Du Mu's heart about Chang'an. Therefore, in teaching, we should pay attention to leading students to grasp the essence of Du Mu's poetry in a comprehensive and in-depth manner.
\end{abstract}

\section{Introduction}

$\mathrm{Du} \mathrm{Mu}$ is a famous poet in the late Tang Dynasty. His predecessors have a high evaluation to him. Chen Zhensun of the South Song Dynasty called his poetry that "The poetry is gorgeous and has a sense of temperament. It is not possible for the late Tang Dynasty." In the Qing Dynasty, Ji Yun also commented that "Du Mu's poetry is more than Yuan and Bai." Both of them praised Du Mu's poetry and spirit in transcending his contemporaries. And Li Shangyin, who was in the same period as $\mathrm{Du} \mathrm{Mu}$, evaluated that only Du Mu's poetry can describe the grieve over the passing of spring and parting of friend beautifully. Then, how does Du Mu's poems contain his style and spirit? It can be seen that Du Mu's "grieve over the passing of spring and parting of friend " is not limited to the general meaning, but also has a deeper emotional connotation. In view of Du Mu's life and the environment of the times, the "grieve over the passing of spring" in his poems is mostly grieve for the time, which is full of worrying about the country and the people. The poems of "grieve over parting of friend", especially those written about Chang'an of the emperor, are full of poet's fascinating career, ambition, and the feelings of the home country. This is the root cause of his poetry with his own style and spirit. In teaching, we should enable students to truly understand the thoughts of home and country contained in Du Mu's poems and cultivate their patriotic feelings.

There are many homesickness in Du Mu's poems, which are full of thoughts about Chang'an in his hometown. He once mentioned the home and country in the poem "Meet a friend at the Winter Solstice and send a letter to brother", expressing his feelings of sorrow, that is, "There is no way to reconcile your country, and you can only remember your brother." This kind of feeling is related to his unique growth experience. Du Mu was born in the famous family and grew up in Chang'an. Jing Zhao Du family is the famous family of Chang'an in Tang Dynasty. His grandfather Du You was the prime minister of the Three Dynasties. He was a great minister, and he was very diligent. He had written a book of "Tong Dian" with two hundred volumes, which made Du Mu very proud. He said to himself: "My family is a famous family and locate in the center of Chang'an, and there are kinds of books in my family." The poetry is full of Du Mu's love and pride for Chang'an and his family. It also makes Du Mu set up the grand ambition of taking the world as his responsibility. He asked himself to be a politician and pay full attention to the real problems of the destiny of the country, such as "the trace of the rise and fall of the chaos, the affairs of the wealthy armies, the danger of the terrain, and the gains and losses of the ancients." His knowledge is more than ordinary people, and it is considered by $\mathrm{Hu}$ Zhenheng that "He has ability to be a prime minister." Chao Gongwu who lived in Song Dynasty also said in his book "Jun Zhai Reading" that "Du Mu is good at writing and dare to talk about major events to point out problems." It can be seen that Du Mu has the enthusiasm, courage and loyalty to actively participate in national events. However, the filthy 
political environment of the late Tang Dynasty lived up to Du Mu' s heroic ambitions. Although he was a scholar, he was repeatedly placed in remote states such as Huangzhou, Chizhou and Muzhou during his prime. Far from Chang'an with depression and resentment made him into the deep thoughts of the Chang'an hometown that once made him proud. The "homeland", "Duling" and "Fanchuan" frequently appearing in his poems all represent Chang'an, which is so mourning for him, filled with deep and lingering thoughts of his home.

$\mathrm{Du} \mathrm{Mu}$ often uses homeland to representative Chang'an. His poems contain about 13 poems containing the meaning of his homeland. This image contains his love for his hometown and his deep feelings for his homeland of Chang'an. For example, one of "Three poems of Zhupo's quatrains" saying that "The pond in old country relies on the canal, and the Jiangcheng Sanchao exchanges fish books. Jia Sheng resigned and hated, and only lived in Changsha.". The first sentence points out that the hometown depends on the canal and land. It is a unique feature of the capital, which is full of pride and thoughts for his homeland. The second sentence summarizes the bumps of his career and the last two sentences are compared with Jia Yi, and express their grievances that have been innocent for many years. Another example is the two sentences of "willow quatrain" that "Fanchuan hate in the old country, half-covering the village bridge and river", which borrows willow to vent his regrets away from the homeland of Chang'an. There are also other sentences, such as "which year of old country, dust crown hanging", "In the old country, only a spring dream remains, and sleep in a lonely boat in a coarse cloth.", etc., all of which show his deep affection for Chang'an.

In Du Mu' s poems, he mentioned many places of Chang'an for many times, such as “ $\mathrm{Du}$ Ling” " Fan Chuan" and "Zhu Po" , all of which represented the hometown of Chang' an in his heart. For example, in the "During the way to Qiu Pu" saying that "Let me ask the geese who have just arrived at the cold sand home. When you came, did you pass through my hometown Duling?" This whispered question contains the ardent thoughts of the hometown and relatives. Another example is "I was in this place during the Spring, and I was really intoxicated by this beautiful scenery. It was like drunkenness and fell before the falling flowers.", "Du Mu was missing his home when drink at foreign land", "The pines and cypresses along the creek of the hometown are paired in pairs. When returning home, they rely on the small window of pine trees. The tombs of the Han Dynasty and the Xiaoyuan of the Sui Dynasty were all extinct following the destruction of the country. In the parade of the autumn night, they crossed the Qingjiang River." and so on, all of which are written about his homesickness. Du Mu also has several poems that miss Zhu Po, such as "Zhu Po", "three poems of Zhu Po quatrains" and "Recalling Zhupo's four rhymes", all of which are also full of affection for his hometown. There are still many rhesis in Du Mu's poems to show his homesickness. For example, "Qi'an City Building" saying that "After rolling the corner of Jianglou, Xiaoyang fell to the cold. You don't have to rely on the bar to look back, the hometown seventy-five long pavilions." The first two sentences show the demise of the rest of the country by the scene of the twilight. The last two sentences have written a strong homesickness with accurate figures and bitter tone. When the poet looks at his hometown Chang'an, his heart is filled with more complicated homeland thinking than ordinary homesickness.

$\mathrm{Du} \mathrm{Mu}$ ' s thoughts on Chang' an stems from his love of the capital and his hometown. He loves the magnificent weather and natural beauty of Chang' an City. Chang'an of his poems is magnificent. In the daytime, "Cuiping Mountain opened to Fengcheng, and the blue sky was shaken", which was magnificent. In the night, "The cold night is quiet, and the enamel is full of heavy cities. Every country is divided, no one has this", which phenomenon is magnificent. Chang'an also has beautiful scenery such as Fanchuan and Zhupo, that is, "The wild bamboo is still dense, and the rock springs are re-flowing. Du Cun Lian Yu Shui, see the hook in the evening" and "Under the Duxiang Garden, the spring sounds around...... Outside the north gate of Qianmen, Nanshan Wugu West. Yichuan Hongyeling, Liansi Green Yangdi" Another example is "Chang'an Qiuwang" saying that "The building is outside the frosty tree, and there is no mirror in the sky. Nanshan and autumn colors, the momentum is high." The Chang'an autumn color in the poem is as high as the Zhongnan Mountain, and the momentum is extraordinary. The contrast between 
Chang'an City and Zhongnan Mountain is the perfect combination of humanistic scenery and natural power.

$\mathrm{Du} \mathrm{Mu}$ is also very concerned about the historical traces of Chang'an City, especially the places related to Emperor Xuanzong of Tang Dynasty. Du $\mathrm{Mu}$ has several poems revealing the ignorance of the emperors represented by Chang'an Huaqing Palace. For example, in the poems of the "three poems of passing through Huaqing Palace quatrains" saying that "The horses rushed to the speed and couldn't see what was contained. Only Yang Guifei looked far away on the mountain, knowing that the most beloved lychee was shipped, and smiled." and "They lied about the military situation. Tang Xuanzong and Yang Guifei still indulged in singing and dancing until An Lushan started his army and the Central Plains was broken." and others. Both are the ironic critiques of Xuanzong's ignorance of the wrongfulness of the country and the good intentions of the ancient satire. Another example is "Passing through the Qinzheng buildi" saying that "The name of the festival is empty, and there is no such thing as the world. Only the purple moss is partial, and it is covered with rain every year.". The poem expressed deep feelings about the depression of the country and the prosperity of the world through the ups and downs of Chang'an Xingqing Palace Qinzheng Building. The glory of the Tang Dynasty has passed away. In the late Tang Dynasty, Chang'an City begin to decline. Du Mu expressed deep concern about the destiny of the country represented by Chang'an City in the "six poems of Chang'an Miscellaneous Long Sentence", and it can be found in the fifth as below.

"The water of Hong he and Wei shui river is very clear, Taibai and Zhongnan mountain axis horizontal. Auspicious clouds reflect the purple of han palace, Chun guang embroidered painting qin chuan Ming. "

"The grass is beautiful, and the wind returns to the son. Liu Fei Nan Xing Furong Court, ten miles of fragrance into the city. "

Zhu Sanxi who lived in Qing Dynasty commented on this poem: "The first sentence writes water of Chang'an, the second sentence writes mountain of Chang'an, third or fourth write Palace of Chang'an, fifth write Chang'an's Jiali, sixth write Chang'an's Ranger, seventh and eighth write directly to Yuyuan, Jiacheng. 'Six Fei Nan Xing' and 'Shi Li Wen Xiang' are so popular and who advocates it? There is irony outside the words." The first six sentences of the poem describe Chang's landscapes and palaces, and the last two sentences express their reflection on the luxury enjoyment of the capital. The other poems in the group have similar disclosures. For example, there is a sentence in the first poem that "There is nothing in the four seas, the general will bring the mirror to the frost", which criticize the court for whitewashing and doing nothing. The sentence in the second poem that "Du Mu laugh at himself without the wisdom like Lou $\mathrm{Hu}$, and he do not know what he have done useful" and the sentence in the third poem that "all people are indulged in pleasure and only Du Mu can see the situation on the ground ", both of them express the sorrow of the poet that he can not realize his ambition. The poet recalled the history of Chang'an, examined the status quo of the capital, and worried about the future of the country, but he can do nothing and was in a state of deep depression and contradictions, which made him be sentimentally attached to his hometown and had to flee Chang'an.

$\mathrm{Du} \mathrm{Mu}$ loves Chang'an but has long served outside of Chang'an. He is mainly affected by the situation of dynasty. Later, he is subjectively chosen by himself. $\mathrm{Du} \mathrm{Mu}$ was forced to leave Chang' an in the prime of political enthusiasm, and his heart was extremely depressed. In his poems, he reflected on his own distressed situation that "he imitate Zhang Wenji no reason, and then be forced to leave home for five years". He thought the reason that he is forced to stay away from Changan just like Zhang Gang who lived in Han Dynasty. However, when Du Mu was appointed to Chang'an in his late years, he made an anomalous move of self-invitation. The reason for this can be seen in Du Mu's poems. In the following two poems, we can see the mood of $\mathrm{Du} \mathrm{Mu}$ when he worked at Changan.

"Qinling Hanyuan is in the snow, and the northern part of the mountain is the second spring. The car was full of the city, and I knew that there were idlers."

"The bird disappeared into vast expanse of the sky, and the remains of ancient times disappeared 
into the ruined Leyou plain. Want to serve the motherland to build a career, the woods of the Wuling are in the bleak and autumn winds."

The first poem wrote winter to spring, Chang'an, a capital city with Qinling Hanyuan, is still bustling, but the poet has no heart to enjoy the spring and is alone in the sigh of sorrow. The latter one wrote that even when he was on the tour, he couldn't stop the sorrow and see the infinite desolateness of the "The woods of the Wuling are in the bleak and autumn winds". Obviously, Du $\mathrm{Mu}$ has been eager to return to Chang'an to serve the country, but the dark turmoil in the late Tang officialdom and the gradual decline of the capital made him intolerant. Therefore, it caused his self-contradictory that he missed Chang'an when he was not in Chang'an, and fled Chang'an when he was in Chang'an. Du Mu wrote poem when he was appointed as Huzhou feudal provincial in his later years that "When you are in the Qing Dynasty, you are incompetent. Want to take a trip to the river, looked at Zhaoling on Leyou plain." The first two sentences are irony, writing the helpless situation of being born and not meeting the time. The last two sentences write that he intends to leave Chang'an but it is difficult to give up his love for Changan. Looking back at the details of Zhaoling, the poet's contradictory mentality and patriotic affection are written. Looking back, there is Du Mu' s cherished love for the Tang Dynasty and his sadness in the disillusionment of his own country. The feelings of worrying about the country in the poem are gloomy and sad. Therefore, no matter where he is, Du Mu' s thoughts about Chang' an have never been reduced.

Compared with other poets, Du Mu's attention to Changan is extremely comprehensive. There are both subjective feelings such as pride and love for the hometown of Chang'an, and rational thinking about the glory of the emperor's Chang'an. It not only comprehensively displays the layout of Chang'an, but also has unlimited worries about the fate of Datang Chang'an. This close combination of Changan's perceptual knowledge and rational examination, the deep concern about Chang'an's current situation and historical destiny, and the intertwining of pride and sentimental sentiment make Chang'an City in Du Mu's poem extremely realistic, full-scale and full of inclusiveness. All of these are derived from the valuable feelings of $\mathrm{Du} \mathrm{Mu}$, who cares about Changan and unforgotten the fate of the country. This is the essence of Du Mu Chang'an poetry, and the root of his poetry has his own style and spirit.

$\mathrm{Du} \mathrm{Mu}$ and Li Shangyin had the same achievement in poetry. Both of them have inherited the spirit of Du Fu's poetry, worrying about the country and the people, and they were called "Little Li Du." However, because Du Mu has a lot of unrestrained words and deeds and poems, it makes the evaluation of later generations more divided, which weakens the reader's cognition of his patriotic feelings in his poems. Therefore, in the teaching of $\mathrm{Du}$ Mu's poems, it is necessary to comprehensively introduce Du Mu's life creation, but also to highlight the essence of the deep and persistent patriotic feelings contained in his poems. When explaining his poetry in detail, it is necessary to have a detailed analysis of words and phrases, and to open up the inner spirit implied in different poems with a macroscopic view. For example, the understanding of Du Mu's poetry for homesickness can not only stay on the side of showing nostalgia, but also should thoroughly analyze all aspects of Chang'an City, and grasp his valuable feelings for Chang'an and his home.

\section{Acknowledgements}

This paper is the result of the Xi'an Social Science Planning Fund Key Project "Research on the Cultural Resources and Appropriate Utilization of the Fanchuan Weidu Family in Changan City, Tang Dynasty", Project No.: 16WL03

\section{Reference}

[1] Z. S. Chen. The book of Zhizhai Book. Beijing: Zhonghua Book Company, 1992.

[2] Y. Ji and others. The book of Siku Quanshu. Beijing: Zhonghua Book Company, 1997.

[3] J. H. Zhang. Compile of Du Mu's Data. Beijing: Zhonghua Book Company, 2006.

[4] Z. Q. Wu. Annual Correction and Note of Du Mu Poetry. Beijing: Zhonghua Book Company, 2008. 
[5] Z. H. Hu. Tang Yingui signed. Shanghai: Classical Literature Press, 1957.

[6] G. W. Chao edit and M. Sun correct. Correction of Jun Zhai Reading. Shanghai: Shanghai Ancient Books Press, 1990. 